\title{
Karakteristik Sarang Tarsius wallacei di Lebanu, Sigi, Sulawesi Tengah
}

\section{Characteristic of Sleeping Site of Tarsius wallacei At Lebanu, Sigi, Central Sulawesi}

\author{
Alferi*), Fahri dan Annawaty*) \\ Jurusan Biologi, Fakultas MIPA Universitas Tadulako, \\ Jl.Soekarno Hatta km 9 Tondo Palu Sulawesi Tengah
}

\begin{abstract}
Tarsius wallacei Merker et al. 2010 is an endemic primate that has distribution in restricted area of Central Sulawesi. The purvosive of this study is describing the characteristic of nest of T. wallacei in their natural habitat in Lebanu, Marawola, Sigi, Central Sulawesi. The observation was based on main variables i.e. species of sleeping tree, character of the nest, tree circle and temperature and humidity of the nest. The additional variable was vegetation around the sleeping site. The mostly sleeping site of T. wallacei in Lebanu was banyan tree (Ficus spp). The character of the tree sleeping site was hollow, relatively dark and many hanging roots around the tree. The altitude of nest from the ground was varying between $4 \mathrm{~m}$ and $7 \mathrm{~m}$. The temperature of the nest varies from $23.12^{0} \mathrm{C}-24.12^{0} \mathrm{C}$ to $25.16^{\circ} \mathrm{C}$ while the humidity varies from $80.8 \%$ to $90.2 \% 81 \%$. The vegetation around the nest was dominated by bandicoot berry (Leea indica) which belongs to Family of Vitaceae.
\end{abstract}

\section{Key words: Tarsius wallacei, Sleeping site, Lebanu, Sulawesi}

\begin{abstract}
ABSTRAK
Tarsius wallacei Merker et al., 2010 adalah primata endemik Sulawesi yang penyebarannya terbatas di Sulawesi Tengah. Penelitian ini bertujuan untuk mendeskripsikan karakteristik sarang T. wallacei di habitat alaminya di Lebanu, Sigi, Sulawesi Tengah. Penelitian menggunakan metode observasi dengan variable utama berupa jenis pohon sarang, bentuk sarang, lingkaran pohon dan serta suhu dan kelembaban sarang, sedangkan variabel penunjang berupa vegetasi di sekitar sarang. Dari hasil penelitian ini ditemukan bahwa sarang T. wallacei di Desa Lebanu adalah pohon Ficus spp dengan karakter pohon berongga, relatif gelap dan memiliki akar gantung yang banyak. Ketinggian sarang dari permukaan tanah bervariasi antara $4 \mathrm{~m}$ sampai $7 \mathrm{~m}$. Suhu sarang tarsius pada pagi hari berkisar antara $23,12^{\circ} \mathrm{C}-24,12^{\circ} \mathrm{C}$ dan pada malam hari berkisar antara $24,96^{\circ} \mathrm{C}-25,16^{\circ} \mathrm{C}$ sedangkan kelembaban berkisar antara $86 \%-90,2 \%$ pada pagi hari dan $80,8 \%-81 \%$ pada malam hari. Jenis tumbuhan di sekitar sarang tarsius di dominasi oleh Leea indica dari Famili Vitaceae.
\end{abstract}

Kata Kunci: Tarsius wallacei, Sarang tidur, Lebanu, Sulawesi 


\section{PENDAHULUAN}

Tarsius wallacei Merker et al, 2010 adalah salah satu fauna endemik Sulawesi yang penyebarannya terbatas di Sulawesi Tengah. Jenis tarsius atau tangkasi ini pertama kali dideskripsi berdasarkan spesimen yang diperoleh dari Uwemanje, Sulawesi Tengah (Merker et al., 2010). Selain T. wallacei, terdapat beberapa jenis tarsius lain di Pulau Sulawesi dan pulaupulau sekitarnya di antaranya Tarsius spectrum (Gursky, 1995, Qiptiyah dan Setiawan, 2012), Tarsius dianae (Niemitz et al., 1991), Tarsius pumilus (Musser et al., 1987), Tarsius lariang (Merker dan Groves, 2006) dan Tarsius tumpara (Shekelle et al., 2008)

Saat ini tarsius masuk dalam satwa yang dilindungi berdasarkan Peraturan Perlindungan Binatang Liar Tahun 1931 dan Peraturan Pemerintah No.7 Tahun 1999. Menurut data International Union for Conservation of Nature (IUCN), Tarsius wallacei dikategorikan sebagai jenis tarsius dengan status data deficient (DD) atau data yang masih kurang mengenai jenis ini. Distribusi T. wallacei di Sulawesi Tengah menyebar di wilayah yang tidak berkesinambungan, jenis ini terbagi menjadi 2 populasi yaitu populasi utara dan selatan yang diisolasi satu sama lain oleh Teluk Palu, kota Palu, dan bagian selatan Isthmus Palu (Merker et al., 2010).
Penyebaran tarsius ini di bagian utara adalah di Batusuya dan Tinombo, sedangkan di selatan adalah di Uwemanje. Sebelah timur Uwemanje adalah Desa Lebanu yang merupakan salah satu wilayah yang termasuk dalam Decamatan Marawola. Desa ini berada lebih kurang 8 $\mathrm{km}$, dari desa Uwemanje.

Berdasarkan hasil penelitian yang telah dilakukan di Desa Lebanu, ditemukan ada enam sarang tidur $T$. wallacei yang semuanya terdapat pada pohon yang tergolong ke dalam genus Ficus dengan karakter pohon berongga, relatif gelap dan memiliki akar gantung yang banyak. Informasi mengenai karakteristik sarang $T$. wallacei yang dideskripsikan dalam tulisan ini diharapkan dapat menjadi informasi penting sebagai bahan rujukan dalam konservasi T. wallacei di Sulawesi.

\section{BAHAN DAN METODE}

\section{Waktu dan Tempat Penelitian}

Penelitian dilaksanakan di kawasan hutan Desa Lebanu Kecamatan Marawola, Kabupaten Sigi, Sulawesi Tengah pada bulan April sampai Mei 2015. Identifikasi sampel tumbuhan dilakukan di Unit Pelaksana teknis (UPT) Sumber Daya Hayati Sulawesi Universitas Tadulako dan Laboratorium Biodiversitas FMIPA Jurusan Biologi Universitas Tadulako. 


\section{Metode Penelitian}

Penelitian ini menggunakan metode observasi dengan cara pengamatan langsung di lokasi penelitian yang dilakukan dalam dua tahap, yaitu: tahap pendahuluan yang dilakukan untuk mencari pohon yang dijadikan sarang oleh tarsius kemudian mengidentifikasi pohon sarang dan selanjutnya melakukan penomoran pohon sarang tarsius di lokasi pengamatan. Tahap selanjutnya adalah tahap pengamatan yang dibagi dalam dua tahap yaitu: penagamatan variabel utama dan variabel penunjang. Variabel utama meliputi: (1) Jenis pohon sarang, yang pengamatannya dilakukan pada siang hari, kemudian diberi tanda (S1 sampai S6). (2) Lingkaran pohon sarang, diukur menggunakan alat pita ukur kemudian dilingkarkan pada pohon sarang tarsius, (3) Bentuk sarang, dengan cara mengamati bentuk sarang, mengambil gambar sarang, kemudian mendeskripsikannya, (4) Ketinggian sarang diukur dari permukaan tanah, dilakukan dengan menggunakan pita ukur, pengukuran dilakukan dengan menentukan tempat pertama kali tarsius terlihat, (5) Suhu dan kelembaban sarang, dengan cara meletakkan thermohygrometer pada sarang Tarsius. Pengambilan data ini dilakukan pada pagi hari pukul 06.00-07.00 saat tarsius kembali ke sarang, pada sore hari pukul 17.00-18.00 saat tarsius keluar dari sarang. Selain variable utama, diukur juga variabel penunjang yang meliputi pengamatan jenis vegetasi sekitar sarang dengan radius $5 \mathrm{~m}$, (Lowing, dkk, 2013). Kemudian mengoleksi semua tumbuhan sebagai bahan herbarium untuk diidentifikasi di UPT Sumber Daya Hayati Sulawesi Universitas Tadulako dan Laboratorium Biodiversitas Jurusan Biologi FMIPA Universitas Tadulako.

Data yang diperoleh dianalisis secara deskriptif kualitatif yakni penguraian dan penjelasan mengenai gambarangambaran umum dari hasil pengamatan secara langsung.

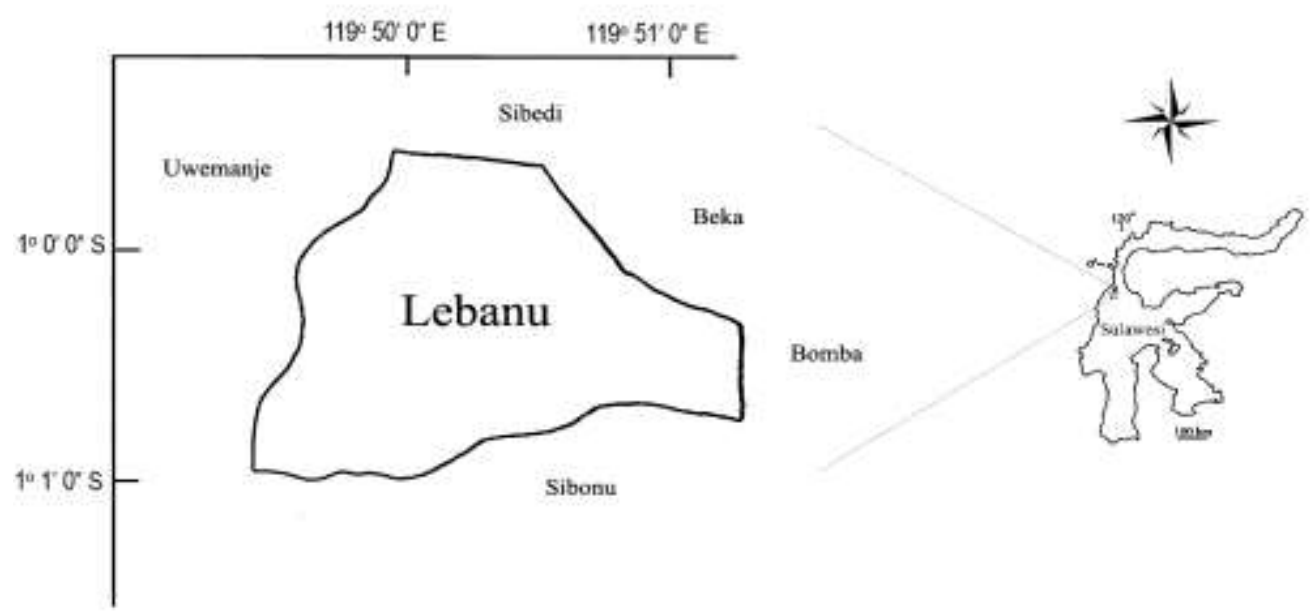

Gambar 1. Peta lokasi penelitian di Lebanu, Marawola, Sigi, Sulawesi Tenga 


\section{HASIL DAN PEMBAHASAN}

\section{Jenis Pohon Sarang}

Dari hasil pengamatan ditemukan ada enam pohon sarang tarsius di kawasan hutan Desa Lebanu. Keenam pohon sarang T. wallacei tersebut merupakan jenis pohon beringin dari jenis Ficus benyamina dan Ficus sp. Pohon Ficus spp mudah dijumpai dan banyak tumbuh di kawasan hutan Desa Lebanu. Pemilihan pohon Ficus sebagai sarang tarsius juga ditemukan pada populasi tarsius di Cagar Alam Tangkoko (Lowing dkk, 2013) dan Suaka Margasatwa Lambusango serta Cagar Alam Kakinauwe di Pulau Buton, Sulawesi Tengara (Mansyur dkk, 2016). Menurut MacKinnon dan MacKinnon (1980) pohon tidur tarsius umumnya memiliki karakteristik umum yang sama yaitu memiliki tingkat cahaya yang rendah dan hampir gelap, memiliki tempat perlindungan dari angin dan hujan, memiliki rongga-rongga dan beberapa pintu keluar untuk melindungi diri dari ular dan predator lainnya.

\section{Lingkaran Pohon Sarang}

Lingkaran pohon sarang berkisar antara 6,14 sampai $11,8 \mathrm{~m}$ (Tabel 1)

Tabel 1 Daftar pohon sarang dan lingkaran pohon

\begin{tabular}{cclcc}
\hline Sarang & Famili & \multicolumn{1}{c}{ Jenis } & Nama lokal & Lingkaran pohon (m) \\
\hline S1 & Moraceae & Ficus benjamina & Nunu & 10,20 \\
S2 & Moraceae & Ficus benjamina & Nunu & 10,10 \\
S3 & Moraceae & Ficus benjamina & Nunu & 12,40 \\
S4 & Moraceae & Ficus sp & Nunu & 8,24 \\
S5 & Moraceae & Ficus benjamina & Nunu & 6,14 \\
S6 & Moraceae & Ficus benjamina & Nunu & 11,80 \\
\hline
\end{tabular}

\section{Bentuk Sarang}

Letak sarang tarsius yang ditemukan di Lebanu umumnya ditemukan pada pohon yang memiliki akar gantung yang banyak (Gambar 2) sehingga dapat digunakan oleh tarsius untuk tempat berpegangan disaat keluar dan masuk ke lubang sarang. Keberadaan akar gantung pada pohon Ficus spp akan membentuk lubang lubang kecil yang saling terhubung satu dengan yang lainya. Selanjutnya lubang inilah yang dimanfaatkan oleh tarsius sebagai tampat berlindung dari hujan, panas matahari dan serangan pemangsa. Sarang tarsius di Desa Lebanu lebih banyak ditemukan pada pohon Ficus sp yang memiliki rongga kecil (Gambar 2). Hal ini disebabkan karena rongga yang kecil dapat menghindarkan tarsius dari panas, hujan dan terutama predator yang aktif di siang hari. 

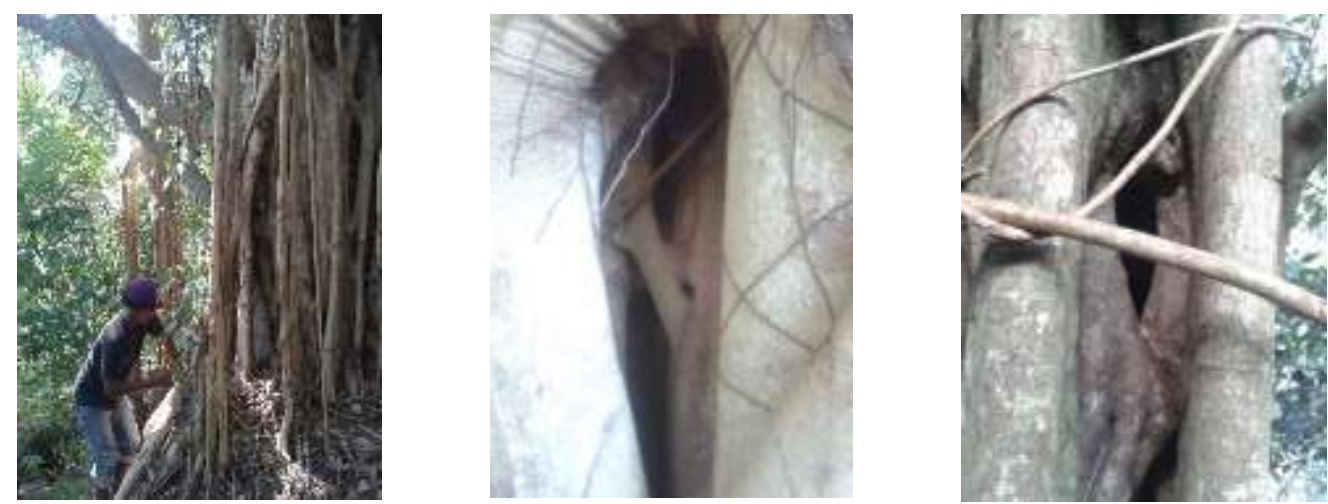

Gambar 2. Gambar 2 Karakteristik bentuk sarang tarsius yang ditemukan di Lebanu

\section{Ketinggian Sarang Dari Permukaan} Tanah

Hasil pengamatan ketinggian sarang dari permukaan tanah (Tabel 2), diketahui bahwa di Desa Lebanu, tarsius banyak mendiami sarang dengan ketinggian yang bervariasi antara $4 \mathrm{~m}$ sampai $7 \mathrm{~m}$. Ketinggian sarang tersebut tidak jauh berbeda dengan yang dilaporkan Wirdateti dan Dahrudin (2006), yang menyatakan bahwa ketinggian sarang tarsius di Cagar Alam Tangkoko berkisar 3m sampai $15 \mathrm{~m}$.

Tabel 2. Ketinggian Sarang dari Permukaan Tanah

\begin{tabular}{|c|c|c|}
\hline Sarang & Spesies & $\begin{array}{c}\text { Jarak dari } \\
\text { permukaan } \\
\text { tanah }(\mathrm{m})\end{array}$ \\
\hline S1 & Ficus Benjamina & 4 \\
\hline S2 & Ficus Benjamina & 5,2 \\
\hline S3 & Ficus benjamina & 5,4 \\
\hline S4 & Ficus sp & 6,2 \\
\hline S5 & Ficus Benjamina & 5,5 \\
\hline S6 & Ficus Benjamina & 7 \\
\hline
\end{tabular}

\section{Suhu dan Kelembaban Dalam Sarang}

Hasil pengamatan suhu pada sarang tarsius diperoleh suhu pagi hari berkisar antara $23,12^{0} \mathrm{C}-24,12^{0} \mathrm{C}$ dan pada malam hari berkisar antara $24,96^{\circ} \mathrm{C}-25,16^{\circ} \mathrm{C}$ (Gambar 3).

Suhu ini mempengaruhi terhadap aktifitas tarsius dihabitatnya. Menurut Qiptiah dan Setiawan (2012) suhu udara habitat tarsius berkisar antara $27,63^{\circ} \mathrm{C}$ $35,87^{\circ} \mathrm{C}$ pada musim penghujan dan pada musim kemarau berkisar antara $28,73^{\circ} \mathrm{C}$ $35,37^{0} \mathrm{C}$.

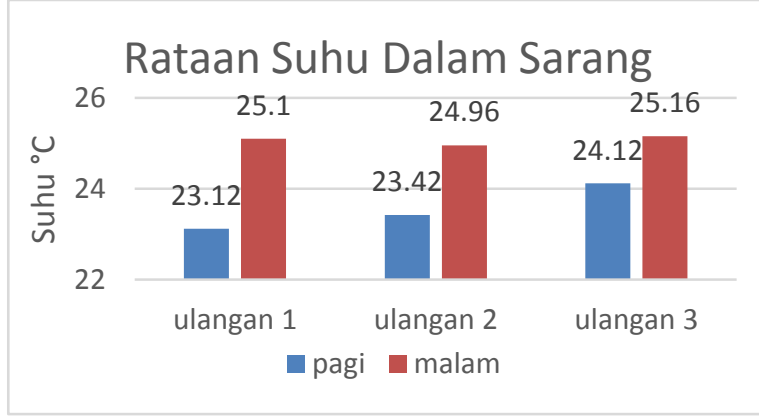

Gambar 3. Hasil pengukuran suhu dalam sarang 
Hasil pengukuran kelembaban dalam sarang tarsius di Desa Lebanu dengan tiga kali pengulangan pada pagi hari dan malam hari. Data hasil pengukuran kelembaban pada pagi hari berkisar antara $86 \%-90,2 \%$ dan malam hari berkisar antara $80,8 \%-81 \%$ (Gambar 4).

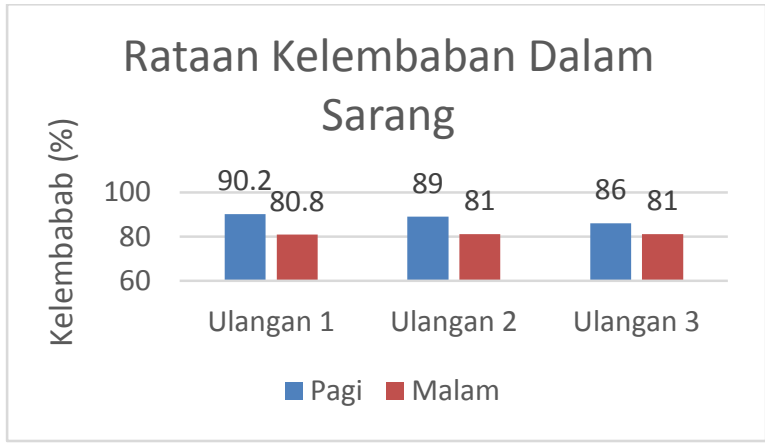

Gambar 4 Hasil pengukuran kelembaban dalam Sarang

Dari hasil pengukuran tersebut, tingkat kelembaban tertinggi dalam sarang terjadi pada pagi hari dikarenakan pada malam hari hutan menjadi lebih basah, sehingga hal ini mempengaruhi tingkat kelembaban. Sedangkan tingkat kelembaban terendah terjadi pada malam hari dikarenakan peningkatan suhu menjadi lebih panas pada siang hari. Kelembaban dalam sarang juga memegang peran penting dalam pertumbuhan tarsius di alam. Tarsius lebih memilih tempat yang sejuk dan agak lembab untuk dijadikan sebagai tempat bersarang, dikarenakan hewan tarsius beradaptasi dengan lingkungan yang dingin. Tarsius memiliki karakteristik eksterior bulu yang tebal, yang membuat tarsius tetep merasa hangat walaupun berada di lingkungan yang dingin. Hal tersebut sesuai dengan yang dilaporkan Lowing dkk. (2013) bahwa tarsius memilih tempat yang sejuk dan agak lembab untuk dijadikan sebagai tempat sarang.

\section{Vegetasi Sekitar Sarang}

Hasil pengamatan jenis vegetasi sekitar sarang dalam radius $5 \mathrm{~m}$ di temukan bahwa dari semua jenis tumbuhan yang berada disekitar sarang tarsius, Leea indica dari Famili Vitaceae adalah tumbuhan yang paling sering ditemukan. Tumbuhan ini ditemukan di semua lokasi penelitian (Tabel 3). Vegetasi tumbuhan di sekitar sarang memiliki peran penting dalam hal aktifitas dari tarsius karena tumbuhan yang berada di sektar sarang akan menjadi faktor penunjang dari sarang utama, ataupun jalan keluar masuknya tarsius kedalam sarang utama

Vegetasi di sekitar sarang tarsius umumnya adalah tumbuhan yang berdiameter kecil sehingga memudahkan tarsius untuk menjadikanya sebagai tempat berpegangan disaat beraktifitas. Hal tersebut juga di laporkan oleh Wirdateti dan Hadi Dahrudin (2006), bahwa hewan tarsius bertubuh kecil dan kebiasaanya melompat vertikal diantara pohon memungkinkan hewan tarsius ini beradaptasi pada tumbuhan berdiameter kecil sampai menengah. 
Tabel 3. Jenis Vegetasi Sekitar Sarang

\begin{tabular}{|c|l|}
\hline Sarang & \multicolumn{1}{|c|}{ Jenis Vegetasi di Sekitar Sarang } \\
\hline S1 & $\begin{array}{l}\text { Leea indica, Caliandra, Scefflera sp, } \\
\text { Leucosyke capitelata, Maceranga } \\
\text { hispida }\end{array}$ \\
\hline S2 & $\begin{array}{l}\text { Leea indica, Caliandra sp, dan } \\
\text { Makaranga hispida }\end{array}$ \\
\hline S3 & $\begin{array}{l}\text { Leea indica, Caliandra sp, Streblus } \\
\text { sp, Acalypha caturus, Fragraea } \\
\text { racemosa }\end{array}$ \\
\hline S4 & $\begin{array}{l}\text { Leea indica, Acalypha caturus, } \\
\text { Leucaena leucocephala, } \\
\text { Poikilospermum suaveolens, } \\
\text { Syzygium sp, Pipturus argenteus }\end{array}$ \\
\hline S5 & $\begin{array}{l}\text { Leea indica, Croton tiglium, } \\
\text { Arcangelesia, Helicia celebica }\end{array}$ \\
\hline S6 & $\begin{array}{l}\text { Leea indica, Croton tinglium, Acer } \\
\text { laurinum dan Helicia celebica. }\end{array}$ \\
\hline
\end{tabular}

Dari hasil penelitian ini dapat disimpulkan bahwa sarang Tarsius wallacei di Desa Lebanu adalah anggota dari Genus Ficus dengan karakter pohon berongga, relatif gelap dan memiliki akar gantung yang banyak. Ketinggian sarang dari permukaan tanah bervariasi antara $4 \mathrm{~m}$ sampai $7 \mathrm{~m}$. Suhu sarang tarsius pada pagi hari berkisar antara $23,12^{\circ} \mathrm{C}-24,12^{\circ} \mathrm{C}$ dan pada malam hari berkisar antara $24,96^{\circ} \mathrm{C}-$ $25,16^{\circ} \mathrm{C}$ sedangkan kelembaban berkisar antara 86\%-90,2\% pada pagi hari dan $80,8 \%-81 \%$ pada malam hari. Jenis tumbuhan di sekitar sarang tarsius didominasi oleh Leea indica dari Famili Vitaceae.

\section{UCAPAN TERIMA KASIH}

Penulis mengucapkan terima kasih kepada Nobertus Bumbungan, S.Si. dan Rio Chalvin Bethony, S.Si. yang telah membantu proses pengambilan data di lapangan, terima kasih juga penulis sampaikan kepada Prof. Dr. Ramadanil M.Si. dan Sahlan, S.Si yang telah membantu proses identifikasi specimen tumbuhan di UPT Sumber Daya Hayati Sulawesi dan Laboratorium Biodiversitas Jurusan Biologi FMIPA Universitas Tadulako.

\section{DAFTAR PUSTAKA}

Lowing, A.E., Rimbing, S.C., Rembet,G.D.G., Nangoy,M.J. 2013. Karakteristik Sarang Tarsius (Tarsius spectrum) di Cagar Alam Tangkoko Bitung Sulawesi Utara. Jurnal Zootek Vol 32 (5): 61-73.

MacKinnon, J. \& MacKinnon, K. 1980. The behavior of wild spectral tarsiers. Int J Primatol Vol 1(4): 361-379. DOI:10.1007/BF02692280

Mansyur F. I., Mustari A.H. dan Prasetyo L.B. 2016. Karakteristik Habitat Tarsius (Tarsius sp.) Berdasarkan Sarang Tidur di Hutan Lambusango Pulau Buton Provinsi Sulawesi Tenggara. Media Konservasi 21(2): 135-142

Merker, S., Driller, C., Dahruddin, H., Sinaga, W., Perwitasari-Farajallah, D. and Shekelle, M., 2010. Tarsius wallacei: A new Tarsier species from Central Sulawesi occupies a discontinuous range. Int. J. Primatol, 31(6), pp. 1107-1122. DOI $10.1007 / \mathrm{s} 10764-010-9452-0$

Merker, S. and Groves, C.P., 2006. Tarsius lariang: A new primate species from western central Sulawesi. Int. J. Primatol, 27(2): 465-485. DOI: 10.1007/s10764-006-9038-z 
Musser, G.G., Dagosto, M. and Raven, H.C., 1987. The identity of Tarsius pumilus, a pygmy species endemic to the montane mossy forests of central Sulawesi. American Museum novitates; no. 2867.

Niemitz, C., Nietsch, A., Warter, S. and Rumpler, Y., 1991. Tarsius dianae: a new primate species from Central Sulawesi (Indonesia). Folia primatologica, 56(2): 105-116.

Gursky, S.L., 1995. Infant care in the spectral tarsier (Tarsius spectrum) Sulawesi, Indonesia. International Journal of Primatology, 16(1): 843853.

Shekelle, M., Groves, C., Merker, S. and Supriatna, J., 2008. Tarsius tumpara: a new tarsier species from Siau Island, North Sulawesi. Primate

Conservation, 23(1): 55-64.

Wirdateti dan H. Dahrudin 2006. Pengamatan pakan dan habitat Tarsius spectrum (tarsius) di kawasan Cagar Alam TangkokoBatu Angus, Sulawesi Utara. Biodiversitas 7 (4): 382-386.

Qiptiyah M, dan Setiawan H. 2012. Kepadatan Populasi dan Karakteristik Habitat Tarsius (Tarsius spectrum Pallas 1779) di Kawasan Patunuang, Taman Nasional BantimurungBulusaraung, Sulawesi Selatan. Jurnal Penelitian Hutan dan Konservasi Alam Vol 9 (4): 363 371. 